\title{
CALCINOSE PERITENDÍNEA dO TENDÃo CALCÂNEO ASSOCIADA A DERMATOMIOSITE: CORRELAÇÃO ENTRE RADIOGRAFIA CONVENCIONAL, ULTRA-SONOGRAFIA, RESSONÂNCIA MAGNÉTICA E MACROSCOPIA CIRÚRGICA*
}

\author{
Ana Cláudia Ferreira Rosa ${ }^{1}$, Edegmar Nunes Costa ${ }^{2}$, Márcio Martins Machado ${ }^{3}$, Válney Luiz \\ da Rocha ${ }^{4}$, Renato Antônio Sernik ${ }^{5}$, Rodrigo Alvarenga Nunes ${ }^{6}$, Marcella Stival Lemes ${ }^{7}$, Lidyane \\ Marques de Paula Gomide ${ }^{7}$, Alexandre Daher Albieri ${ }^{8}$, Rubens Carneiro dos Santos Júnior ${ }^{9}$, \\ Nestor de Barros ${ }^{10}$, Giovanni Guido Cerri ${ }^{11}$
}

Resumo A calcinose intersticial é uma afecção incomum, na qual existe deposição de cálcio localizada ou disseminada na pele, tecido celular subcutâneo, músculos e tendões. Freqüentemente a calcinose está associada com doenças do tecido conjuntivo, como esclerodermia e dermatomiosite. Os autores relatam um caso de calcinose intersticial associada a dermatomiosite, estudada com radiografia convencional, ultra-sonografia, ressonância magnética, e com correlação com a macroscopia cirúrgica.

Unitermos: Calcinose; Calcinose intersticial; Dermatomiosite; Radiografia convencional; Ultra-sonografia; Ressonância magnética.

Abstract Peritendinous calcinosis of calcaneus tendon associated with dermatomyositis: correlation between conventional radiograph, ultrasound, magnetic resonance imaging and gross surgical pathology.

Interstitial calcinosis is an uncommon condition in which there is either localized or widely disseminated deposition of calcium in the skin, subcutaneous tissues, muscles, and tendons. Calcinosis is often associated with collagen diseases, scleroderma and dermatomyositis. The authors report a case of interstitial calcinosis associated with dermatomyositis studied with conventional radiograph, ultrasound and magnetic resonance imaging, and correlate the imaging findings with the results of surgical pathology gross examination.

Key words: Calcinosis; Interstitial calcinosis; Dermatomyositis; Conventional radiograph; Ultrasound; Magnetic resonance imaging.

\section{INTRODUÇÃO}

A calcinose intersticial é uma afecção incomum, na qual existe deposição de cálcio localizada ou disseminada na pele, te-

* Trabalho realizado no Centro de Diagnóstico do Hospital de Acidentados de Goiânia, Goiânia, GO, no Departamento de Radiologia do Hospital das Clínicas da Faculdade de Medicina da Universidade de São Paulo (HC-FMUSP) e no Centro de Diagnóstico do Hospital Sírio Libanês, São Paulo, SP.

1. Médica Radiologista do Hospital das Clínicas da Faculdade de Medicina da Universidade Federal de Goiás (FM-UFG), Doutora em Radiologia pela FMUSP, Radiologista do Centro de Diagnóstico do Hospital de Acidentados de Goiânia.

2. Professor e Chefe do Grupo de Pé do Departamento de Ortopedia da FM-UFG, Chefe do Grupo de Pé do Hospital de Acidentados de Goiânia.

3. Professor Convidado do Departamento de Radiologia da FM-UFG, Chefe do Centro de Diagnóstico do Hospital de Acidentados de Goiânia, Doutor em Radiologia pela FMUSP.

4. Professor e Chefe do Grupo de Quadril do Departamento de Ortopedia da FM-UFG, Chefe do Grupo de Quadril do Hospital de Acidentados de Goiânia.

5. Chefe da Divisão de Radiologia Músculo-Esquelética do Instituto de Radiologia (InRad) do HC-FMUSP e do Centro de Diagnóstico do Hospital Sírio Libanês.

6. Acadêmico de Medicina da Faculdade de Ciências Médicas da Universidade do Vale do Sapucaí (Univas).

7. Acadêmicas de Medicina da FM-UFG. cido celular subcutâneo, músculos e tendões. Freqüentemente, a calcinose está associada com doenças do tecido conjuntivo, como esclerodermia e dermatomiosite. Entretanto, pode existir sem associação com qualquer doença ${ }^{(1)}$.

Neste artigo os autores apresentam um caso de calcinose localizada na região peritendínea do tendão calcâneo insinuandose para a musculatura da panturrilha.

8. Ortopedista, Membro do Grupo de Pé do Hospital de Acidentados de Goiânia.

9. Professor do Departamento de Radiologia da FM-UFG, Chefe do Serviço de Ressonância Magnética do Instituto de Neurologia de Goiânia.

10. Professor Doutor do Departamento de Radiologia da FMUSP.

11. Professor Titular do Departamento de Radiologia da FMUSP, Chefe do InRad/HC-FMUSP, Diretor do Centro de Diagnóstico do Hospital Sírio Libanês.

Endereço para correspondência: Dr. Márcio Martins Machado. Rua 1027, no 230, Edifício Fabiana, ap. 304, Setor Pedro Ludovico. Goiânia, GO, 74823-120. E-mail: marciommachado@ ibest.com.br

Recebido para publicação em 28/10/2004. Aceito, após revisão, em 10/2/2005.

\section{RELATO DO CASO}

Paciente do sexo feminino, 15 anos de idade, em acompanhamento por ser portadora de dermatomiosite há seis anos, referindo aumento progressivo de volume no contorno posterior do terço inferior da perna, associado a dor à deambulação. Ao exame físico observou-se aumento de volume localizado, adjacente ao contorno posterior do tendão calcâneo.

Foi solicitada radiografia convencional (RX), que mostrou calcificação indo desde o nível da borda superior do osso calcâneo até a panturrilha (Figura 1). O exame de ultra-sonografia (US) revelou, também, a grande extensão da calcificação (Figura 2). No exame de ressonância magnética (RM) (Figura 3) identificou-se a calcificação com aspecto tubuliforme, posteriormente ao tendão calcâneo, indo desde as adjacências do osso calcâneo até a panturrilha. 


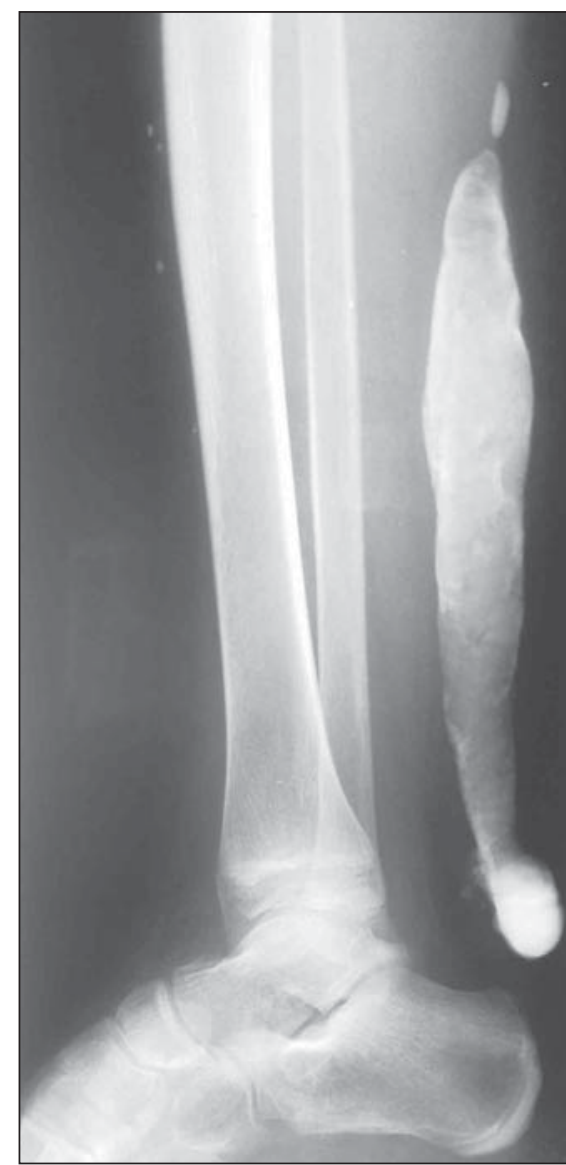

Figura 1. Raio $X$ demonstrando a calcificação envolvendo a topografia do tendão calcâneo em direção à panturrilha.

O Grupo de Pé do Hospital de Acidentados de Goiânia optou pela abordagem cirúrgica. Durante a cirurgia foi identificada calcificação de aspecto tubuliforme, adjacente e em relação ao contorno posterior do osso calcâneo (peritendínea), indo desde as proximidades do contorno superior do osso calcâneo até a junção miotendínea na panturrilha (Figura 4). A calcificação foi removida em toda a sua extensão, evidenciando-se que ela não comprometia a substância do tendão calcâneo.

\section{DISCUSSÃO}

Didaticamente, pode-se dividir a calcinose em universal (difusa) e circunscrita. A calcinose universal (difusa) é caracterizada pela presença de calcificações laminares, em placas, de vários tamanhos, disseminadas pelas partes moles, especialmente o tecido subcutâneo, e ocasionalmente nos músculos e tendões ${ }^{(\mathbf{1})}$, podendo
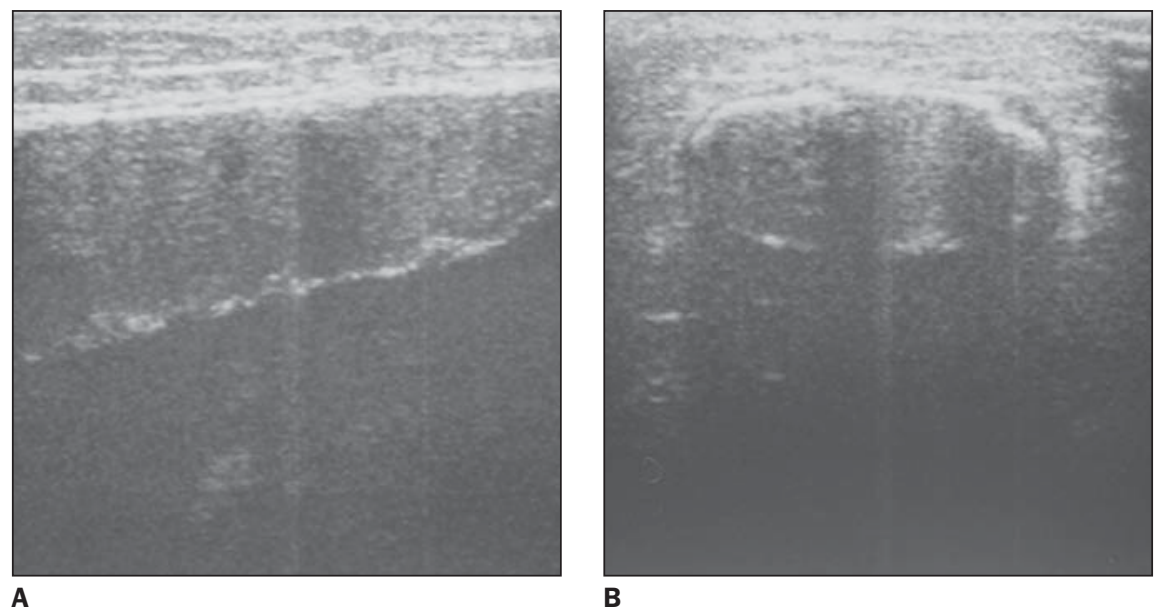

Figura 2. Ultra-sonografia demonstrando a calcificação peritendínea.

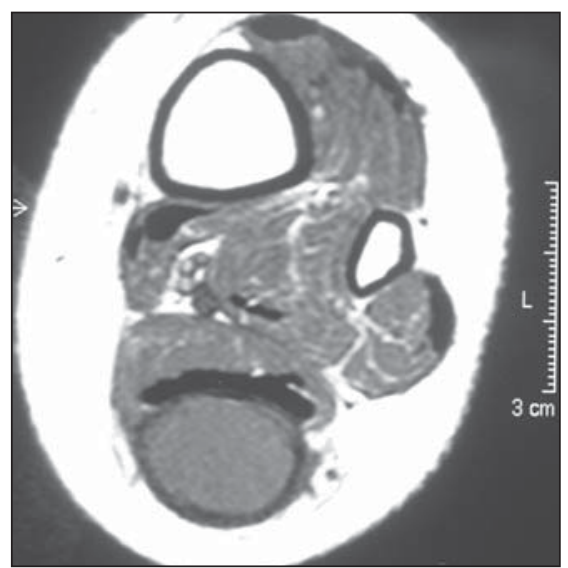

A
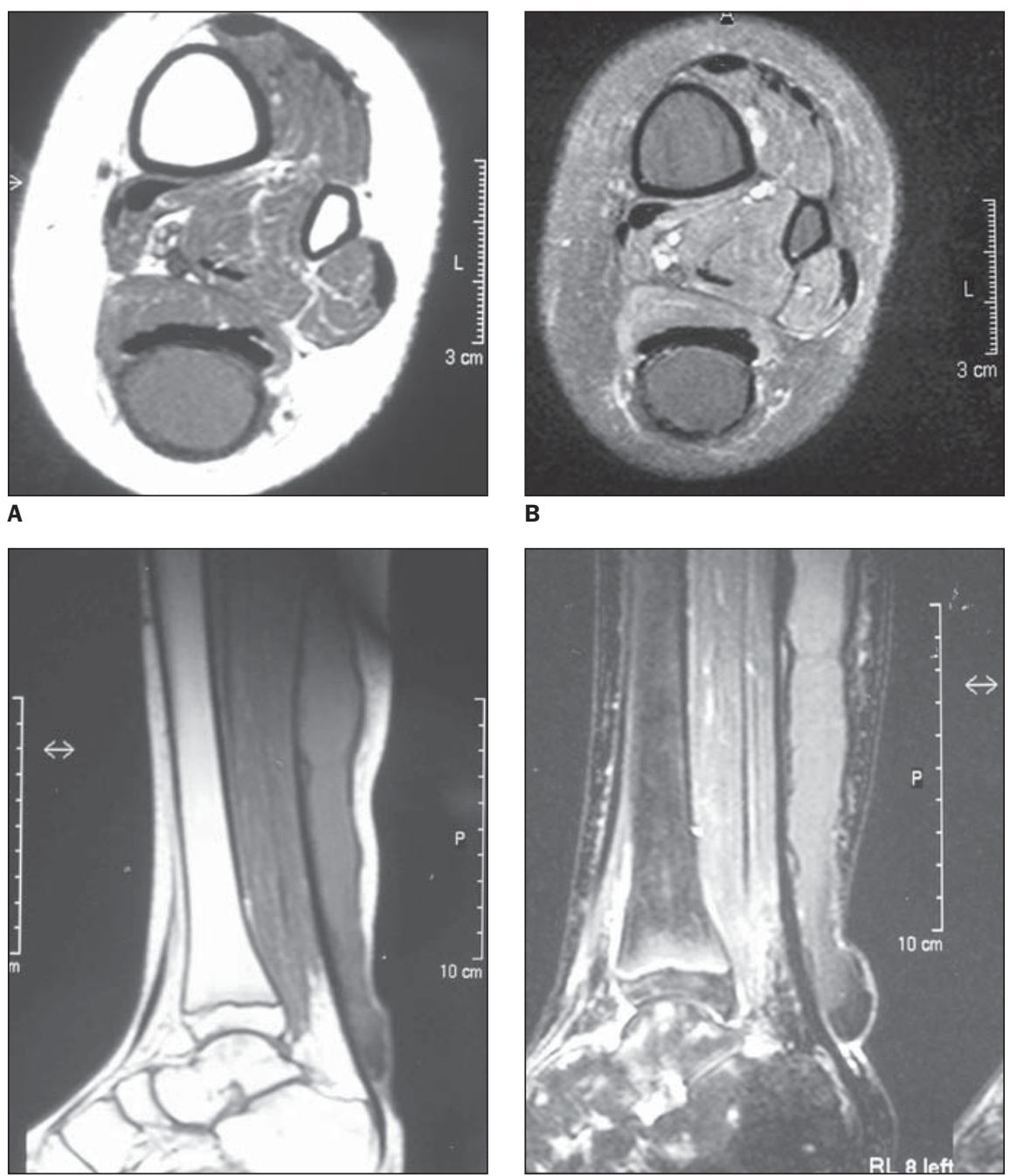

C

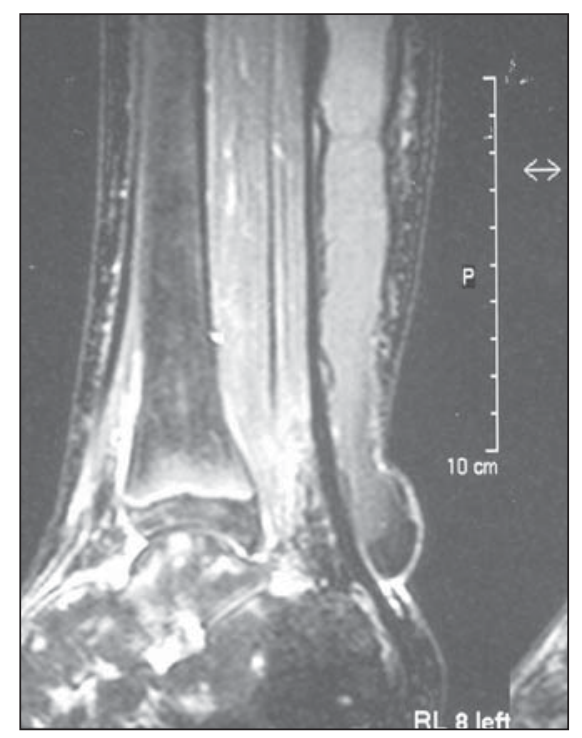

D

Figura 3. A: Imagem axial ponderada em T1 evdidenciando a calcificação peritendínea. B: Imagem axial ponderada em T2/SPIR demonstrando a calcificação peritendínea. Imagem sagital ponderada em T1 (C) e T2/SPIR (D) demonstrando a calcificação adjacente ao tendão calcâneo, indo desde a porção inferior do tendão calcâneo em direção à panturrilha. 


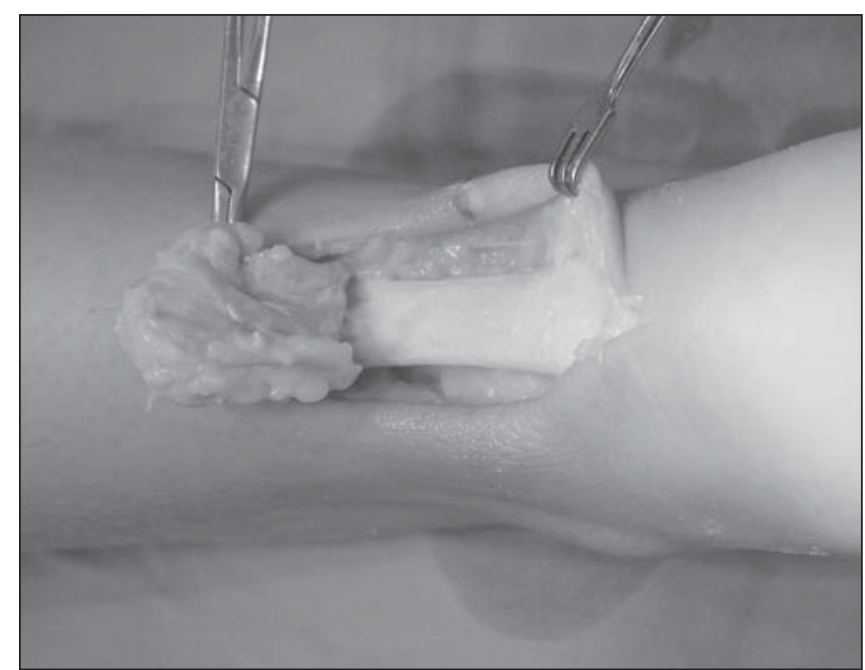

A

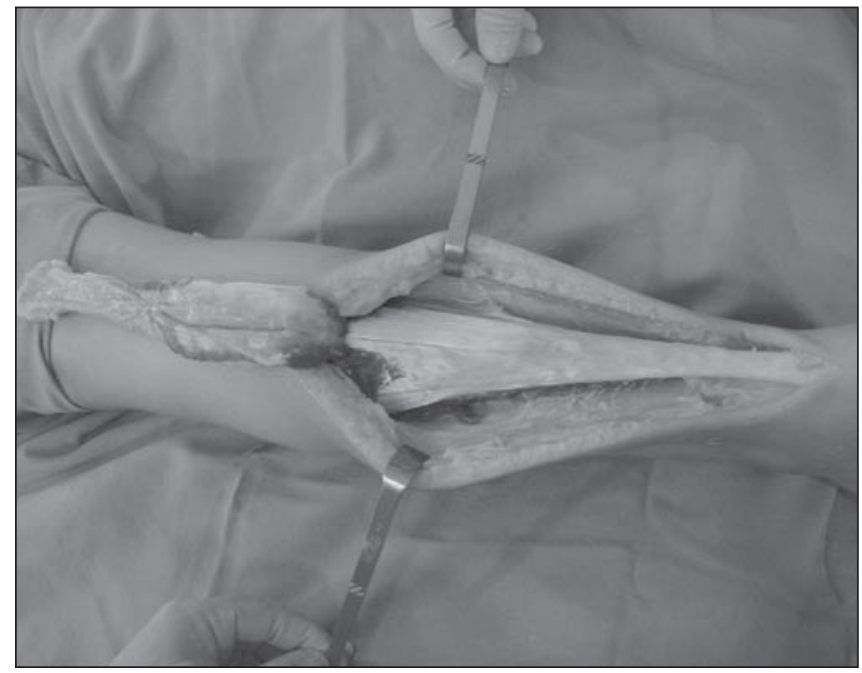

C

Figura 4. Macroscopia durante a cirurgia. A: Início da dissecção da calcificação, separando-a do contorno posterior do tendão calcâneo. B: Imagem operatória demonstrando grande parte da calcificação já separada do tendão calcâneo. C: Tendão calcâneo liberado da calcificação, que se encontra rebatida superiormente. D: Aspecto após a remoção completa da calcificação, com o tendão calcâneo completamente liberado da calcificação.

acometer também os planos fasciais ${ }^{(2-4)}$ Do ponto de vista clínico, existem vários tipos de calcinose difusa: a) forma assintomática, que é rara; b) forma difusa, associada à esclerodermia, incluindo a síndrome CREST (calcinose, fenômeno de Raynaud, hipomotilidade esofagiana, esclerodactilia e telangiectasia); c) calcinose difusa associada a dermatomiosite ${ }^{(\mathbf{1})}$.

$\mathrm{Na}$ esclerodermia e na dermatomiosite as calcificações ocorrem como finas placas. $\mathrm{Na}$ esclerodermia as calcificações seriam limitadas à pele e ao tecido subcutâneo adjacente. Já na dermatomiosite as calcificações podem acometer adicionalmente $\mathrm{o}$ plano muscular ${ }^{(\mathbf{1 , 2})} \mathrm{e}$, segundo Resnick ${ }^{(3)}$, os depósitos cálcicos podem aparecer nos

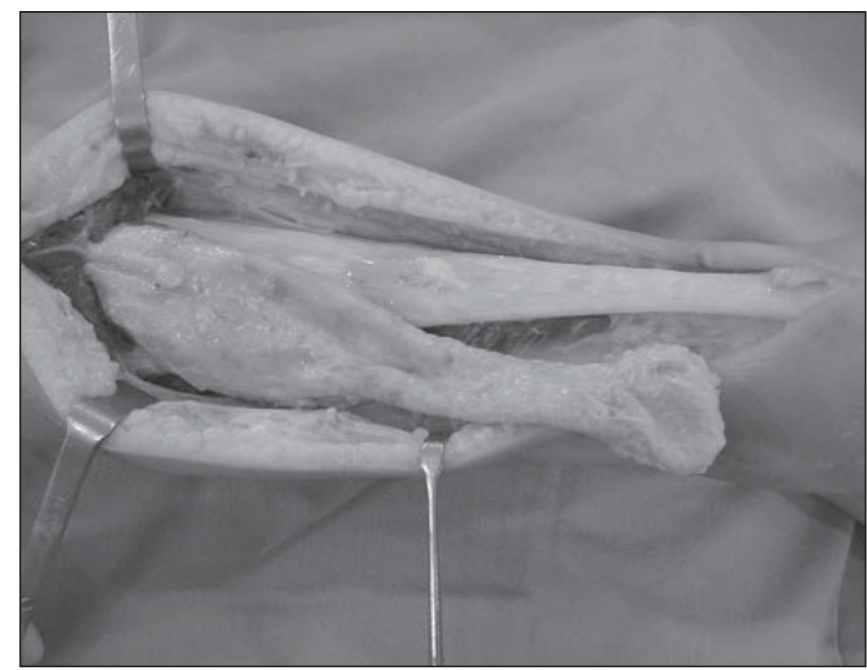

B

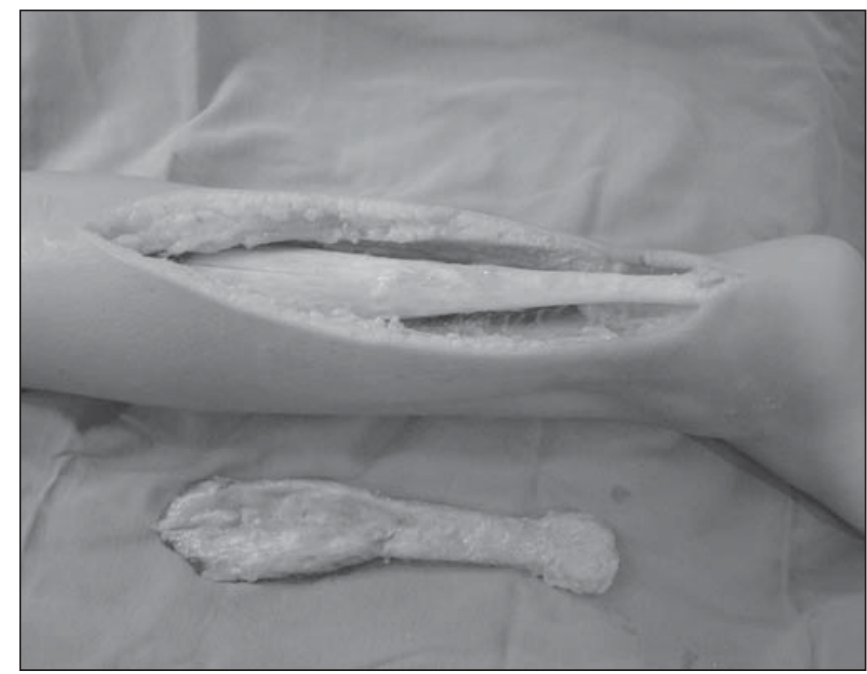

D planos fasciais intermusculares, achado raramente visto em outras doenças do tecido conjuntivo.

Outros autores ${ }^{(\mathbf{1})}$ dividem, didaticamente, a forma de apresentação dos depósitos cálcicos na esclerodermia e na dermatomiosite. Nessas alterações, as calcificações apareceriam em quatro padrões distintos: massas superficiais, massas profundas, depósitos lineares profundos e depósitos rendilhados e reticulados no subcutâneo, que tendem a envolver o tronco. Este último padrão tem importância clínica, por estar associado com tendência de piora progressiva.

A calcinose circunscrita (localizada) caracteriza-se pela deposição de cálcio na forma de focos pequenos e arredondados de calcificação, amórficos. Essas calcificações são encontradas, principalmente, nas extremidades dos dedos e nas margens das articulações das mãos e dos dedos dos pés. Essas alterações são encontradas mais freqüentemente nas mãos do que nos pés, $\mathrm{e}$ quando presentes nas duas localidades, usualmente são mais intensas nas mãos. Da mesma forma que para a calcinose difusa, a calcinose circunscrita ocorre em diferentes situações clínicas: a) não associada a fenômenos vasoespásticos, sendo mais comum em idosos e no sexo feminino; b) associada a esclerodermia, sendo comum as calcificações adjacentes às falanges terminais e nas margens das articulações ${ }^{(\mathbf{1})}$. 
No caso relatado neste trabalho a calcificação foi observada envolvendo a região peritendínea do tendão calcâneo, desde a sua porção mais distal, estendendo-se proximalmente, para envolver a junção miotendínea, sem envolvimento muscular ou do subcutâneo propriamente dito. A calcificação se apresentava como se formasse uma "capa" em torno do contorno posterior do tendão calcâneo e da junção miotendínea.

A possibilidade de compararmos os achados do RX, da US e da RM com os da cirurgia fornece oportunidade única de correlação imagem-patologia cirúrgica, enriquecendo a percepção anatômica e diagnóstica da calcinose.

\section{CONCLUSÃO}

Os autores concluem que, mesmo sendo pouco usuais, as formas diversas de calcinose ocorrem, e adicionalmente, a correlação entre os métodos de diagnóstico com a macroscopia cirúrgica enriquece a compreensão anatômica desta alteração.

\section{REFERÊNCIAS}

1. Rogers LF, Boles CA, Propeck P. The superficial soft tissues. In: Juhl JH, Crummy AB, Kuhlman JE, editors. Paul and Juhl's Essentials of radiologic imaging. 7th ed. Philadelphia, Pa: LippincottRaven, 1998;329-369.

2. Rogers LF. Diseases of the joints. In: Juhl JH, Crummy AB, Kuhlman JE, editors. Paul and Juhl's Essentials of radiologic imaging. 7th ed. Philadelphia, Pa: Lippincott-Raven, 1998;83-127.

3. Resnick D. Dermatomyositis and polymyositis. In: Resnick D, editor. Bone and joint imaging. Philadelphia, Pa: WB Saunders, 1996;305-308.

4. Blane CE, White SJ, Braunstein EM, Bowyer SL, Sullivan DB. Patterns of calcification in childhood dermatomyositis. AJR 1984;142:397-400. 